www.jmscr.igmpublication.org

Impact Factor 5.84

Index Copernicus Value: 83.27

ISSN (e)-2347-176x ISSN (p) 2455-0450

crossref DOI: https://dx.doi.org/10.18535/jmscr/v5i8.68

Journal Of Medical Science And Clinical Research

\title{
To study the efficacy of Obturator Nerve blocks using nerve stimulator in Transurethral Resection of Bladder Tumor (TURBT) under spinal anaesthesia
}

\author{
Authors \\ Dr Rajesh V Nagmothe ${ }^{1}$, Dr L. F. Vali ${ }^{2}$ \\ ${ }^{1}$ Associate Professor, Department of Anaesthesia, Government Medical College and Super Specialty \\ Hospital, Nagpur, Maharashtra \\ ${ }^{2}$ Associate Professor, Department of Anaesthesia, Government Medical College and Super Specialty \\ Hospital, Nagpur, Maharashtra \\ Corresponding Author \\ Dr Rajesh V Nagmothe \\ 44, Panchdeep Nagar, Wardha Road, Near Redison Blu Hotel, Nagpur, Maharashtra \\ Email: rajeshnagmothe@gmail.com, Phone No 9323602314
}

\begin{abstract}
This was a prospective randomized study, conducted to evaluate the efficacy of Obturator Nerve blocks using nerve stimulator in Transurethral Resection of Bladder Tumor (TURBT) under spinal anaesthesia.

Aim and Objectives: To study the effectiveness of Obturator nerve block given by nerve stimulation technique to block the adductor jerk under spinal anaesthesia during Transurethral Resection of Bladder Tumor (TURBT).

Material and Methods: Total 60 patients, aged between 45 and 70 years belonging to ASA physical status I-III, having inferolateral wall and bladder neck tumors that were scheduled for transurethral resection of bladder tumor at risk for electrical stimulation as determined by the attending surgeon and divided them into Group I and II. Patient in Both Group I and Group II received Inj Bupivacaine (0.5\% hyperbaric/ heavy) for subarachnoid block. In Group II patients, after spinal anaesthesia was given Unilateral or bilateral Obturator Nerve block was given depending on the site of tumor by Nerve Stimulation technique using $10 \mathrm{ml}$ of $0.75 \%$ Ropivacaine. During the operative procedure, the primary endpoint of the study was resectability of the tumor whether it hampered or unhampered by adductor reflex under spinal anaesthesia. Complications like bleeding and bladder perforation were the secondary endpoints of this study.

Results: Only $5(16.66 \%)$ patients in Group I, which does not received the Obturater nerve block, have no or minimum adductor muscle jerk in intraoperative period but 25 (83.33\%) patients had significant adductor muscle jerk and required general anaesthesia with muscle relaxation for continuation of procedure. In Group II in which the Obturator nerve block is given after spinal anaesthesia only one patient(3.33\%) required general anaesthesia and 29 (96.66\%) patients was operated in spinal anaesthesia with Obturator nerve block. The incidence of bladder perforation which is a serious complication was $6.6 \%$ in Group I and there is no incidence of bladder perforation in Group II. Total requirement of blood product are significantly more in Group I (16.66\%) as compare to Group II (2.66\%).

Conclusions: Transurethral resection of the bladder tumor can be perform successfully under spinal anaesthesia, supplemented with Obturater Nerve block using nerve stimulation technique with minimum side effect. Thus, Obturater nerve block has become an essential component of spinal anesthesia for TURBT.

Keywords: Transurethral resection of bladder tumor (TURBT), Adductor spasm, Obturator nerve block, Spinal anaesthesia.
\end{abstract}




\section{Introduction}

TURBT is a procedure in which bladder tumors was removed from the bladder wall. This is a procedure performed completely with a scope that is inserted through the urethra into the bladder.

TURBT can be performed under General anaesthesia or the regional anaesthesia. Regional anaesthesia offers many advantages such as technical ease of performing the procedure, reduced risk of bleeding, and early recognition of bladder perforation ${ }^{1}$. As the patients are generally older having multiple comorbid condition, regional anaesthesia associated with less morbidity $^{2}$. The only shortcoming with subarachnoid block is sparing of the Obturator nerve which passed close to lateral wall of bladder tumor can get stimulate due to electric current resulting sudden adductor muscle contraction with a potential complication of bladder rupture or injury, during transurethral resection of bladder (TURBT). This risk is increased in resection of lateral wall tumors as electrosurgical resection of these lesions is more likely to inadvertently stimulate the Obturator nerve resulting in deep cut into bladder that may cause bladder perforation and profuse bleeding ${ }^{3,4}$

\section{The aim of this study was:}

To compare the efficacy of Obturator nerve block using the nerve stimulation technique in Transurethral resection of bladder tumor (TURBT) under subarachnoid block.

\section{Materials and Methods}

This randomized prospective study was carried out in the department of anaesthesiology in Super Speciality Hospital in Urosurgery Operation Theater. After obtaining institutional approval and written informed consent, the study was conducted from March 2016 to may 2017.

We selected 60 patients, aged between 45 and 70 years belonging to ASA physical status I-III, having inferolateral and bladder neck tumors that were scheduled for transurethral resection of bladder tumor at risk for electrical stimulation as determined by the attending surgeon and divided them into Group I and II. Each group comprise of 30 patients. Pre-existing Obturator nerve injury, thigh adductor muscle weakness, infection at the site of injection, abnormal coagulation studies, any contraindication to spinal anaesthesia and patient who refuse to give consent for participation in study are excluded from this study.

A detailed preoperative evaluation including medical history, physical examination, vital signs, laboratory tests and concurrent medical assessment was done for all the patients. Detail cardiac evaluation was done in patients with cardiac complaint. All patients received tablet Alprazolam $0.5 \mathrm{mg}$ orally on the night prior to surgery. Routine preoperative fasting guidelines were followed in all the patients. Patients were evaluated again in the morning in Operation Theater. In the operation theatre standard Multipara monitor with electrocardiogram, NIBP and pulse-oximeter was applied to the patient for recording of ECG and NIBP and SPO2. After securing IV access, all patients were preloaded with IV Ringer Lactate 5 to $6 \mathrm{ml} / \mathrm{kg}$ over 10 minutes.

Sixty patients were divided into two equal groups of 30 patients in each group using the sealed envelope technique. Patient in Both Group I and Group II received Inj Bupivacaine $(0.5 \%$ hyperbaric/ heavy) for subarachnoid block. The dose of Inj Bupivacaine for subarachnoid block was decided after taking into consideration about patient characteristic like age, height and weight. Under all aseptic precaution subarachnoid block was given in sitting position using $23 \mathrm{G}$ spinal needle through L3 -L4 spinal inter space. After spinal anaesthesia was given, patient was made to lie supine for period of 10 minutes. The onset of sensory and motor block was tested every 2 minutes. In Group I after the 10 minutes and adequate sensory and motor anaesthesia achieved, Lithotomy position was given and surgical procedure stared.

In Group II patients, after spinal anaesthesia was given Unilateral or bilateral Obturator Nerve block was given depending on site of tumor by 
Nerve Stimulation technique using $10 \mathrm{ml}$ of 0.75 $\%$ Ropivacaine. The patient was in supine position, with limb to be blocked at 30 degree abduction. The pubic tubercle is identified by palpation and a $1.5 \mathrm{~cm}$ long line drowns laterally and caudally at 45 degree. Nerve stimulation is began using $3 \mathrm{~mA}(1 \mathrm{~Hz})$ and reduce to $0.4-0.6 \mathrm{~mA}$ before injecting $10 \mathrm{ml}$ of $0.75 \%$ Inj Ropivacaine after negative aspiration ${ }^{5}$.

Intra operative all patient are monitor by Multipara monitor (ECG, NIBP and $\mathrm{SpO} 2$ parameters). 15 minutes after giving the subarachnoid block and confirming sensory and motor blockage lithotomic position was given.

In both the group TURBT procedure was started using cystoscope and resection of bladder tumor was perform using Bipolar cautery to resects the tumor with the loop .

During the operative procedure, the primary endpoint of the study was resectability of the tumor, whether it hampered or unhampered by adductor reflex under spinal anaesthesia. Adductor reflex defined as jerky adduction, and external rotation of the thigh at hip joint and number of interruptions. Bleeding and bladder perforation were the secondary endpoints. All patients who had unresectibility due to adductor jerk were managed under general anesthesia with muscle relaxation. Intraoperative complication like bladder perforation and requirement of blood transfusion due to bleeding is noted.

Statistical analysis was performed using SPSS software. The data were tabulated as a mean \pm standard deviation and significance was analyzed by using independent sample $t$ test and Chi-square test. Statistical significance was set at $\mathrm{P}<0.05$.

\section{Observations and Results}

Table No 1: Patients demographic Data

\begin{tabular}{|c|c|c|c|}
\hline Variables & $\begin{array}{l}\text { Group I } \\
(\mathrm{N}=30)\end{array}$ & $\begin{array}{c}\text { Group II } \\
(\mathrm{N}=30)\end{array}$ & P Value \\
\hline Age ( yrs) & $65.65 \pm 12.15$ & $64.25 \pm 14.65$ & \multirow{6}{*}{$\begin{array}{l}\text { P value } \\
>0.05\end{array}$} \\
\hline Male & $24(80 \%)$ & $22(73.33 \%)$ & \\
\hline Female & $6(20 \%)$ & $8(26.66 \%)$ & \\
\hline ASA I & $8(26.66 \%)$ & $6(20.00 \%)$ & \\
\hline ASA II & $20(66.66 \%)$ & $24(80.00 \%)$ & \\
\hline ASA III & $2(6.66 \%)$ & 0 & \\
\hline $\begin{array}{l}\text { Duration of surgery } \\
\text { (min) - }\end{array}$ & $45.33 \pm 15.18$ & $44.16 \pm 14.93$ & $\begin{array}{l}0.5508 \\
(>0.05)\end{array}$ \\
\hline
\end{tabular}

Table no. 1 show the demographic profiles of patients in both Group I and Group II. Patients in both the groups were comparable with regards to age, sex , ASA Status and duration of surgery and difference was statistically not significant ( $p$ $>0.05$ ). Both the groups have older patients with average age around $65 \mathrm{yrs}$ and nearly $60 \%$ patients belong to ASA grade II. This indicate most of patients posted for TURBT are older and had increase risk of anaesthesia and surgery.

Table No 2: Obturator Nerve Stimulation during TURBT

\begin{tabular}{|c|c|c|c|}
\hline Event & $\begin{array}{l}\text { Group I } \\
(\mathrm{N}=30)\end{array}$ & $\begin{array}{l}\text { Group II } \\
(\mathrm{N}=30)\end{array}$ & P Value \\
\hline $\begin{array}{l}\text { No/minimum Adductor } \\
\text { Jerk }\end{array}$ & $5(16.66 \%)$ & $\begin{array}{c}29 \\
(96.66 \%)\end{array}$ & \multirow[t]{4}{*}{$\mathrm{P}$ value $<0.01$} \\
\hline $\begin{array}{l}\text { Requirement of General } \\
\text { anaesthesia due to } \\
\text { Adductor Jerk }\end{array}$ & $\begin{array}{c}25 \\
(83.33 \%)\end{array}$ & $\begin{array}{c}1 \\
(3.33 \%)\end{array}$ & \\
\hline Bladder perforation & $2(6.6 \%)$ & 0 & \\
\hline $\begin{array}{l}\text { Requirement of Blood } \\
\text { Transfusion }\end{array}$ & $5(16.66 \%)$ & $2(6.66 \%)$ & \\
\hline
\end{tabular}

From the Table no 2 we can conclude that the patients in Group I which does not received the Obturater nerve block, only $5(16.66 \%)$ patients have no or minimum adductor muscle jerk in intraoperative period and 25(83.33\%) patient had significant adductor muscle jerk and required general anaesthesia with muscle relaxation for continuation of procedure. In Group II in which the Obturator nerve block is given after spinal anaesthesia only one patient required general anaesthesia and majority of patients that is 29 $(96.66 \%)$ patients get operated in spinal anaesthesia with Obturator nerve block. The incidence of bladder perforation which is a serious complication was $6.6 \%$ in Group I and there is no incidence of bladder perforation in Group II. Total requirement of blood product are significantly more in Group I (16.66\%) as compare to Group II $(2.66 \%)$. The difference in the two groups was statistically highly significant. This indicates the importance to block the Obturator nerve in Transurethral resection of bladder tumor (TURBT) under spinal anaesthesia. 


\section{Discussion}

Bladder cancer has high prevalence and a low mortality, being largely a chronic disease. Data on environmental and genetic factors involved in the disease outcome are inconclusive ${ }^{6}$.

Carcinoma of urinary bladder occurs mainly in older people. About 9 out of 10 people with this cancer are over the age of 55 years. The average age at the time of diagnosis is 73 years and men are about 3 to 4 times more likely to get bladder cancer during their lifetime than women ${ }^{7}$. In this study the average age of patients are 65 years and $65 \%$ to $80 \%$ patients belong to ASA grade II. In view of the older patients having multi systemic disorder and as TURBT is shorter duration of surgery, spinal anaesthesia has advantage over general anaethesia. The only shortcoming with subarachnoid block is sparing of the Obturator nerve which passed close to lateral wall of bladder tumor can get stimulate due to electric current resulting sudden adductor muscle contraction with a potential complication of bladder rupture or injury during transurethral resection of bladder (TURBT). As the subarachnoid block act on the spinal nerve roots and not on neuromuscular junction. There are several mechanisms for preventing the Obturator reflex. Pharmacologic paralysis can reliably inhibit thigh adduction. Spinal anesthesia does not reliably prevent the Obturator reflex. Regional anesthesia is another potential treatment modality to prevent the Obturator reflex during TURBT. Motor blockade of the Obturator nerve will prevent this adduction in the event of inadvertent nerve stimulation. Peripheral blockade of the Obturator nerve can be combined with either general or spinal anesthesia. Various methods have been described in literature to block Obturator nerve. Prentiss et $\mathrm{al}^{8}$ and later Parks and Kennedy ${ }^{5}$ described nerve stimulation technique with a success rate between $83.8 \%$ and $85.7 \%$. The success rate with nerve stimulation was very high in our study $(96.66 \%)$. More recent studies have reported that the use of sonography which was associated with higher success rates of $97.2 \%$ in ultrasound-guided ONB procedures ${ }^{9,10}$.
This is slightly higher than nerve stimulation technique but availability of USG machine is a problem. According to Augspurger and Donohue $^{11}$, effectiveness of abolishing Obturator jerk with blind anatomic approach was $83.8 \%$ which is lower to nerve stimulation and ultrasound-guided techniques described above. As per Gasparich et $\mathrm{al}^{12}$ and Kobayashi et $\mathrm{al}^{13}$ when the nerve stimulation method use, the effectiveness reaches between $89.4 \%$ and $100 \%$. Kuo $^{14}$ and Khorrami et al. ${ }^{15}$ described the transvesical blockade of Obturator nerve with 10 $\mathrm{ml} 1 \%$ Lignocaine injected through cystoscope along with spinal anesthesia (thirty patients) and compared it with spinal anesthesia only group (thirty patients). In the intervention group, 34 ONB were performed. They observed a significant jerk in the control group (16.5\%) compared to the intervention group (3\%).

In our study, we found that patients in Group I , only $16.66 \%$ patients had no or minimum adductor jerk and TURBT procedure can perform under spinal anaesthesia, where as $83.33 \%$ patients required general anesthesia with muscle relaxation for completion of surgery.

In Group II Patients in which Obturater nerve block was given with nerve stimulator, the success rate of block was $96.66 \%$ and only one patient require general anaethesia for TURBT procedure. The incidence of bladder perforation which is a serious complication was $6.6 \%$ in Group I and there is no incidence of bladder perforation in Group II. Total requirement of blood product are significantly more in Group I (16.66\%) as compare to Group II $(2.66 \%)$. This indicates that In Group II patients due to blockage of Obturater nerve Transurethral resection of bladder tumor was perform without any interruption and there was no incidence of bladder perforation and lesser requirement of blood transfusion.

\section{Conclusion}

Transurethral resection of the bladder tumor (TURBT) can be perform successfully under spinal anaesthesia if it is supplemented with 
Obturater Nerve block using nerve stimulation technique with minimum side effect. Thus, Obturater nerve block has become an essential component of spinal anesthesia for TURBT.

\section{Acknowledgement}

We sincerely thank the Department of Anesthesia, Super specialty Hospital and Government Medical College, Nagpur, Maharashtra, for providing facility and granting permission to carry out the work.

Financial support: nil.

Source of support: nil

Conflict of interest: nil.

\section{References}

1. Deepak Sharma et al, Obturater Nerve Block in Transurethral resection of bladder tumor, A Comparative Study by two Techniques Anesth Essays Res. 2017 JanMar; 11(1): 101-104.

2. Cesur M, Erdem AF, Alich HA, Yapanoglu T, Yuksek MS, Aksoy Y; The role of succinylcholine in the prevention of the obturator nerve reflex during transurethral resection of bladder tumors, Saudi Med J 2008; 27: 668-671.

3. Mydlo JH, Weinstein R, Shah S, Solliday M, Macchia RJ; Long-term consequences from bladder perforation and/or violation in the presence of transitional cell carcinoma: results of a small series and a review of the literature. J Urol 1999; 161: 1128-32.

4. Junne-Yin Kuo; Prevention of Obturator Jerk during Transurethral Resection of Bladder Tumor, JTUA 19:27-31, 2008.

5. Parks C R, Kennedy et al, Obturator nerve block : A simplified approach. Anaesthesiology 28:775-778,1967.

6. Real FX et al, Hematol Oncol Clin North Am. 2015 Apr;29(2):177-89.

7. Michael Jurewicz et al, Approaching the optimal transurethral resection of a bladder tumor, Turk J Urol. 2014 Jun; 40(2): 7377.

8. Prentiss RJ et al,Massive adductor muscle contraction in transurethral surgery: Cause and prevention; development of electrical circuitry. J Urol.1965;93:263-71.

9. Lee $\mathrm{SH}$ et al,. Ultrasound guided obturator nerve block: A single interfascial injection technique. J Anesth. 2011;25:923-6.

10. Akkaya Tet al. Ultrasound-guided Obturator nerve block: A sonoanatomic study of a new methodologic approach. Anesth Analg. 2009;108:1037

11. Donohue RE et al, Prevention of obturator nerve stimulation during transurethral surgery. J Urol. 1980;123:170-2..

12. Gasparich JP, Mason JT, Berger RE et al. Use of nerve stimulator for simple and accurate obturator nerve block before transurethral resection. J Urol. 1984;132:291-3.

13. Kobayashi M, Takeyoshi Set al. A report of 107 cases of obturator nerve block. Jpn J Anesth. 1991;40:1138-43.

14. Kuo JY et al, Prevention of obturator jerk during transurethral resection of bladder tumor. JTUA.2008;19:27-31.

15. Khorrami MH, Javid A et al. Transvesical blockade of the obturator nerve to prevent adductor contraction in transurethral bladder surgery. J Endourol. 2010;24: 1651-4. 